\title{
Optimizing Cash Flow of Construction Projects through Different Bid Pricing Schemes
}

\author{
Mohamed M. Gaber1,*, Emad E. Etman2, Haytham M. Sanad3, Mohamed M. Marzouk4 \\ ${ }^{1}$ Demonstrator at Structural Eng. Dept., Faculty of Engineering, Tanta University, Egypt \\ ${ }^{2}$ Professor of Concrete Structures, Structural Eng. Dept., Faculty of Engineering, Tanta University, Egypt \\ ${ }^{3}$ Lecturer at Structural Eng. Dept., Faculty of Engineering, Tanta University, Tanta, Egypt \\ ${ }^{4}$ Professor of Construction Project Management, Structural Eng. Dept., Faculty of Engineering, Cairo University, Egypt \\ * Corresponding author, E-mail address: eng.m_magdy124@yahoo.com
}

\begin{abstract}
Successful construction projects should meet the planning and design objectives within budget and time constraints. Planning and scheduling for the construction projects and their resources are essential tasks for overall project success. Cash, in particular, is an important resource for construction companies. It is worth noting that while pricing bill of quantities in unit price contracts, the contractor might ignore the related cash flow which may be insufficient for contractor. Further, the resulted financial threats also might be ignored. Therefore, it is important for the contractor to have an overall optimized system to improve all financial aspects related to the contract. This paper presents a cash flow optimization model that aims at maximizing cumulative concurrent investment profit (CCIP) and minimizing maximum monthly overdrafts $\left(\mathrm{O}_{\mathrm{Max}}\right)$. The model utilizes Genetic Algorithms for optimization. The performance of the developed model is validated using an actual case study of "Beni Suef Power Station Project" located in Beni Suef, Egypt.
\end{abstract}

Keywords: Construction projects; Cash Flow, Concurrent Investment, Cost Estimating, Bill of Quantities, multiobjective optimization, Non Sorting Genetic Algorisms.

\section{INTRODUCTION}

The construction industry is considered to be one of the riskiest sectors due to the high level of uncertainty involved. Every year, thousands of contractors face bankruptcy and business failure. Among 918,483 U.S. general contractors, operative builders, heavy construction contractors, and specialty-trade contractors operating in 2010 , only 696,441 were still in business in 2012, a 24.2\% failure rate (Surety Information Office 2012). Moreover, only $47 \%$ of U.S. startup businesses in construction were still operating after four years (Statistic Brain 2014). Construction projects represent a huge investment by large sectors of organizations and society (Onomehebhor 2006). The diversity of types, forms, and shapes of construction projects make the construction industry exceptional; other factors such as the geographical dispersion, the labor force and contractual relationships contribute to the uniqueness of construction industry (Mojahed 2005). Due to risks that are inherent to the construction and many tasks that must be performed, the construction contractor must carefully plan, schedule, and manage projects in the most efficient manner.

\section{LITERATURE REVIEW}

Cash flow management aims at achieving many objectives such as cash flow prediction, optimization, and monitoring and controlling. Reliable knowledge of project cash flow is essential for an effective project management. Since the natures of projects are uncertain and easily affected by different criteria, considering uncertainty has become a vital part of any effective project management approach (Mohagheghi et al. 2017).

In order to enhance cash flow, the initial solution should be optimized to minimize the financial commitment of the contractor and to adjust the income and expense statement. The net present value (NPV) of a project's cash flow is usually the preferred criterion of its profitability (Warszawski and Sacks 2004). As quoted by Baroum and Patterson (1996), Russell (1970) was the first to consider the objective of maximizing the NPV of project cash flow. Arafa (1998) introduced a mathematical model for cash flow optimization. The main objective of the model is to maximize the NPV of cash flow by relaxing the activity duration or reallocating project activities. Elazouni and GabAllah (2004) developed an integer-programming model to devise finance-based schedules. The model revises activities start times to produce minimum duration schedules that correspond to desired credit limits (financial constraint). Elazouni and Metwally (2005) stated that, since the execution of construction projects demands huge investments, contractors rarely rely on own savings to carry out projects. Thus, the procurement of cash, termed as financing, has always been the first concern of contractors. Most contractors establish bank overdrafts to finance cash requirements of projects.

The contractor then should load the markup on the estimated cost to get the project price. Markup loading is done by two steps for analysis: the first step is determining optimum bids in a competitive-bidding situation where each competitor submits one closed bid. Further studies explored competitor utility theory (Awwad and Ioannou 2012) and competitor correlation and its influence on markups (Yuan 2011).

After setting the total bid price in the first step, the second step is to unbalance the markup to maximize its net present value (NPV), while keeping the total bid price unchanged. Cattell (1987) explored a comprehensive formulation for the NPV of the contractor's profit, which considered the time value of money (TVM), retainage off progress payments, and risk. Tong and Lu (1992) developed a model that was 
focused solely on optimizing the advantage of what they called "error exploitation unbalancing" referred to by Green (1986) as "individual rate loading", this method ignored the other benefits in the areas of cash flow and escalation. Cattell (2008) have provided a comprehensive basis by which to quantify an item's potential contribution to a project's overall profitability. The basis proposed incorporates all three standard effects of item price loading: namely, front-end loading, individual-rate loading, and backend loading. The model was formulated so as to maximize a project's revenue and not its profit. Christodoulou (2008) advocated that entropy, which is an index of disorder, should be used in an unbalanced bidding model to reach both maximum NPV and minimum financial disorder. Afshar and Amiri (2010) used fuzzy linear programming to model uncertainties in unit prices, quantities, and constraints. Cattell (2011) applied cumulative prospect theory from microeconomics to calculate the bidder's profit expectation at different risk levels for different pricing options. Lucko and Su (2015) added unbalanced bidding to the complexity of cash flow models and provided a new model that can calculate different scenarios accurately and efficiently.

\section{CASH FLOW MODELING}

Analysis of cash flow begins by loading activities with their cost. Subsequently, project cumulative cost, revenue, expense, and income can be calculated. Typical cash flow profile contains cumulative expense and income (Fig. 1). The contractor can know an approximate value of his monthly expenses and the estimated monthly incomes. The cumulative expense curve often has an S-shape, while the income profile of the periodical payments received for doing the work takes a ladder shape. Income payments are calculated from revenue values considering payment delay period from the owner. Revenue values are calculated from cost values considering markup $(\mathrm{M})$ percentage, i.e. revenue $=$ cost $*(1+\mathrm{M})$. Part of cost may be paid immediately (immediate expense) while another part may be delayed or transferred to a later time period (transferred expense). Accordingly, expense values depend on the timing of the contractor payments to his/her suppliers and vendors. The difference between the two curves (expense and income) represents the amount of finance on which interest is charged in case of Ex $>$ In. Financial charge (FC) represents the cost of financing this amount of money. Financial charge can be reduced by getting the expenses lower (through cheaper costs and/or credit from suppliers) and/or by getting the income profile higher (e.g., receiving an advanced payment). From net cash flow profile, the contractor can know the monthly overdraft $(\mathrm{O})$ that should be spent from his own cash until receiving payment. After acquiring cash flow profiles, they should be evaluated to decide whether it is adequate or needs further enhancements.

Hegazy (2001) indicated that the area enclosed between the expense profile and the owner payment (income) profile is the area of financing (Fig. 1). It is possible to estimate the financial charge directly from this area. In addition, Elazouni and Metwally (2005) and Hegazy (2001) introduced an algorithm to determine financial charge considering compound interest effect of monthly overdrafts using Eq. (2).

$$
\begin{aligned}
& \hat{F}_{n}=\left(O_{n}+\sum_{i=1}^{n-1} \hat{F}_{i}\right) r \\
& \mathrm{FC}=\sum_{n=1}^{N} \hat{F}_{n}
\end{aligned}
$$

Where: FC is the financial charge affected by compound interest, $F^{\wedge} n$ is the interested financial charge at period no. $n$ $(n=1$ to $N), N$ is the total number of periods (usually in months), $\mathrm{O}_{\mathrm{n}}$ is the overdraft at period $\mathrm{n}$, and $\mathrm{r}$ is the interest rate in the period.

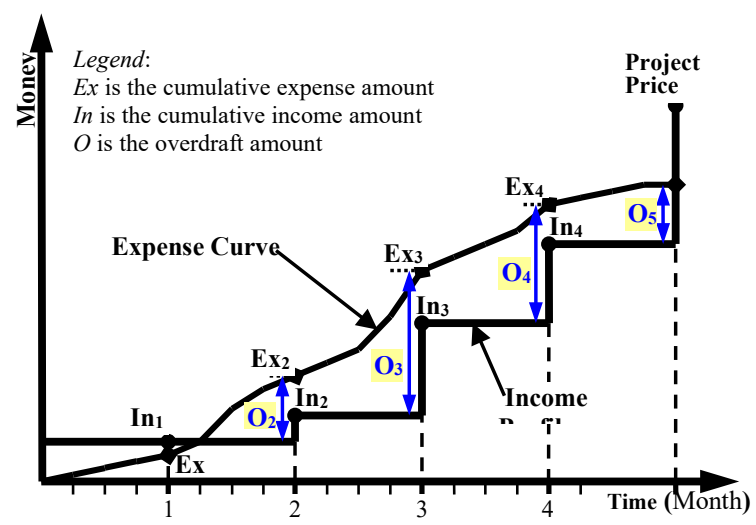

Figure 1. Cash flow curves (Sanad 2011)

Figure 2 illustrates monthly financial charges; for example, financial charge of the first month is calculated as the multiplication of monthly interest rate and the overdraft in this month. While in other months, it is the multiplication of monthly interest rate and all preceding monthly financial charge plus the overdraft of this month. It is also important to maintain maximum monthly overdraft $\left(\mathrm{O}_{\max }\right)$. Minimizing $\mathrm{O}_{\max }$ ensures optimization of cash flow.

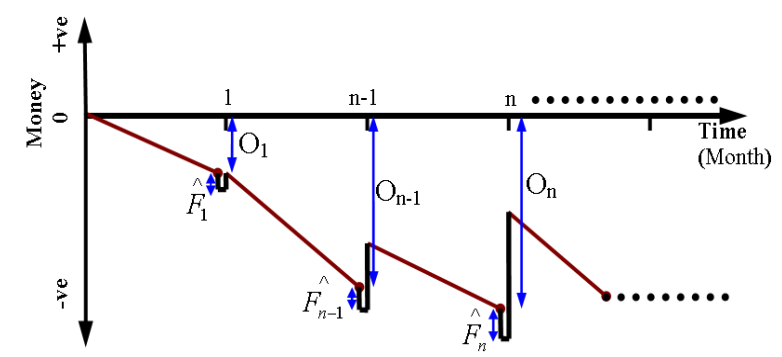

Figure 2. Generation of financial charge from overdrafts (Elazouny and Metwally 2005)

The Cumulative Concurrent Investment Profit (CCIP) is defined as making parallel investment value of the difference between expense (Ex) and income (In). This leads to an increase in the accumulated profit of the contractor and this may make the contractor reduces the tender price and thus enhances the chance of winning the tender against other contractors as shown in Fig. 3 to Fig. 5. However, this assumption of investing some money from the project is 
constrained by several realistic constrains such as the model takes in to consideration that the amount of invested money is not required by the project for any purchasing or expense for three consecutive months at least. This period ensure that concurrent investment is economically feasible. In order to optimize construction cash flow as demonstrated above; Genetic Algorithms optimization technique is used. Eqs. 3 to 5 are used to determine CCIP considering compound interest effect.

$$
C I_{i}=\left(E_{i}-\operatorname{In}_{i-1}\right)^{*}(1+r)^{n}
$$

Where: Cli is the Concurrent Investment in time period $\mathrm{i}$, Exi is the cumulative expense amount in time period i, Ini-1 is the cumulative income received in previous time period $i$, $r$ is the interest rate in the period, and $n$ is the total number of invested periods at least three consecutive months starting on the time of invested amount (IA) (usually in months).

$$
\begin{gathered}
\mathrm{CIP}_{\mathrm{i}}=\mathrm{CI}_{\mathrm{i}}-\mathrm{CI}_{\mathrm{i}-1} \\
\mathrm{CCIP}=\left(\sum_{\mathrm{i}=0}^{\mathrm{N}} \mathrm{CIP}_{\mathrm{i}}\right)
\end{gathered}
$$

Where: CIPi is the Concurrent Investment Profit in one period (usually in months), CCIP is the Cumulative Concurrent Investment Profit and $\mathrm{N}$ is project duration

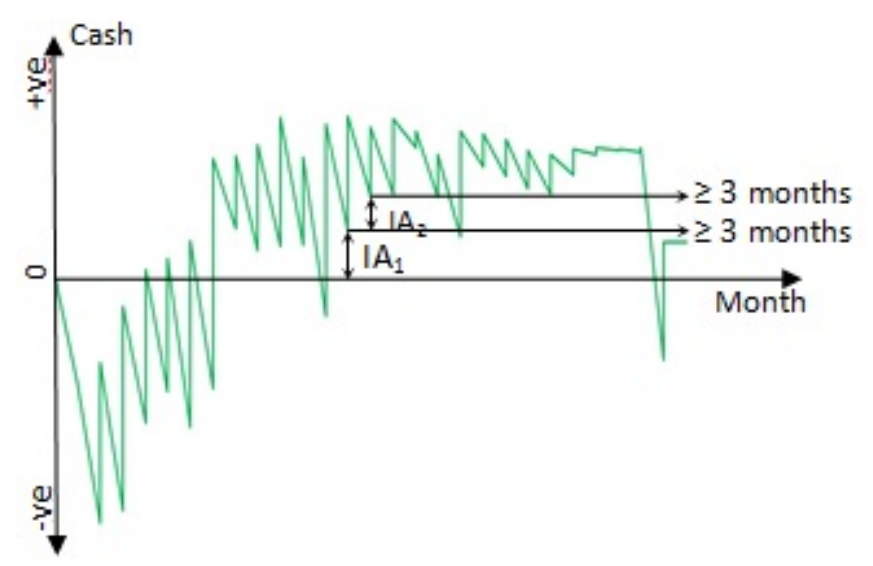

Figure 3. Invested amount of cash (IA)

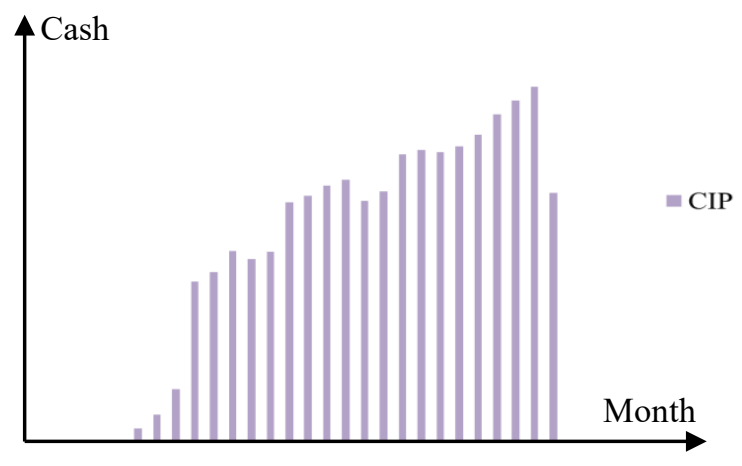

Figure 4. Concurrent Investment Profit (CIP)

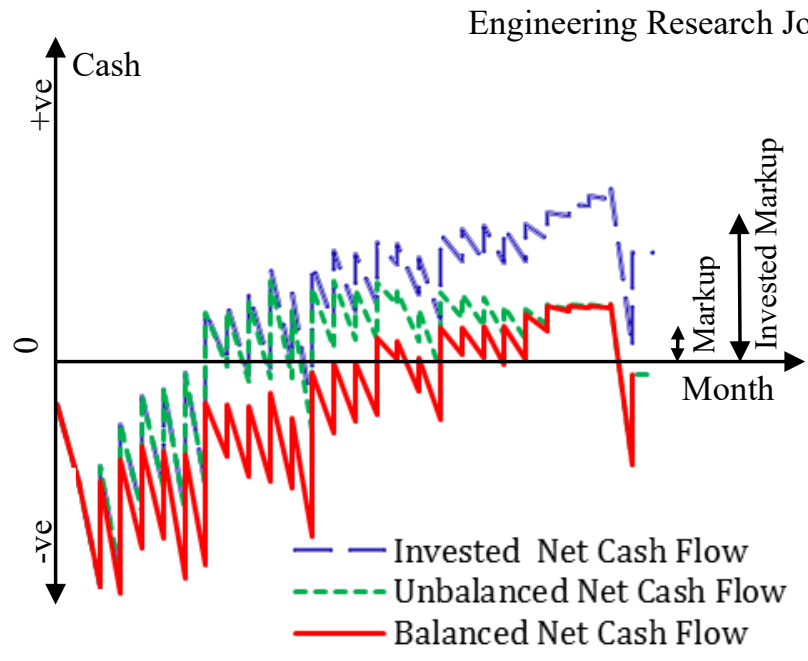

Figure 5. Net cash flow vs. Invested net cash flow

\section{MODEL IMPLEMENTATION}

As outlined before, negative cash flow affects project financing costs, ultimate profit and CCIP. Therefore, control of the cash flow enables schedulers to devise BOQ items that maximize project profit and CCIP. Previous system is attempts to minimize negative cash to avoid a budget deficit without delaying project completion. Figure 6 shows a flowchart of the proposed methodology. Figure 7 illustrates a flowchart of cash flow determination. The main objective of the problem can be stated as optimizing the project CCIP and $\mathrm{O}_{\max }$ as in Eq. (6):

$$
\begin{array}{r}
\mathrm{OF}=(1) \mathrm{Min}: \mathrm{O}_{\max } \\
\text { (2) Max: CCIP }
\end{array}
$$

In solving a problem with multiple objectives, different methods can be employed. In this model, the Pareto optimal solution set approach is used. The objective of the Pareto front concept is to find the set of optimum solutions (Pareto Front). Then the preferred solution, the one most desirable to the Decision Maker (DM), is selected from this set. A solution belongs to the Pareto set (set of non-dominated solutions) if there is no other solution that can improve at least one of the objectives without degradation of any other objective. Fig. 8 illustrates the concept of Pareto-optimality considering two objectives (CCIP and Omax). The feasible region is the region represents all feasible solutions for all objective functions of the system. These solutions satisfy the system constraints, but the optimal solutions lies on the outer most lower-left edge of the feasible region (in case of minimization). The set of Pareto-optimal solutions are generally called Pareto Front (Fig. 8).

1-Optimization process using GA starts to search for the best scenario of the project according to predefined objective functions. In this step, Cash flow is forecasted from linking activities with available BOQ items to generate multiples of scenarios with different activities costs that calculated from BOQ items price. Project scenarios are generated using GA processes which are reproduction, crossover, and mutation. Then each scenario 


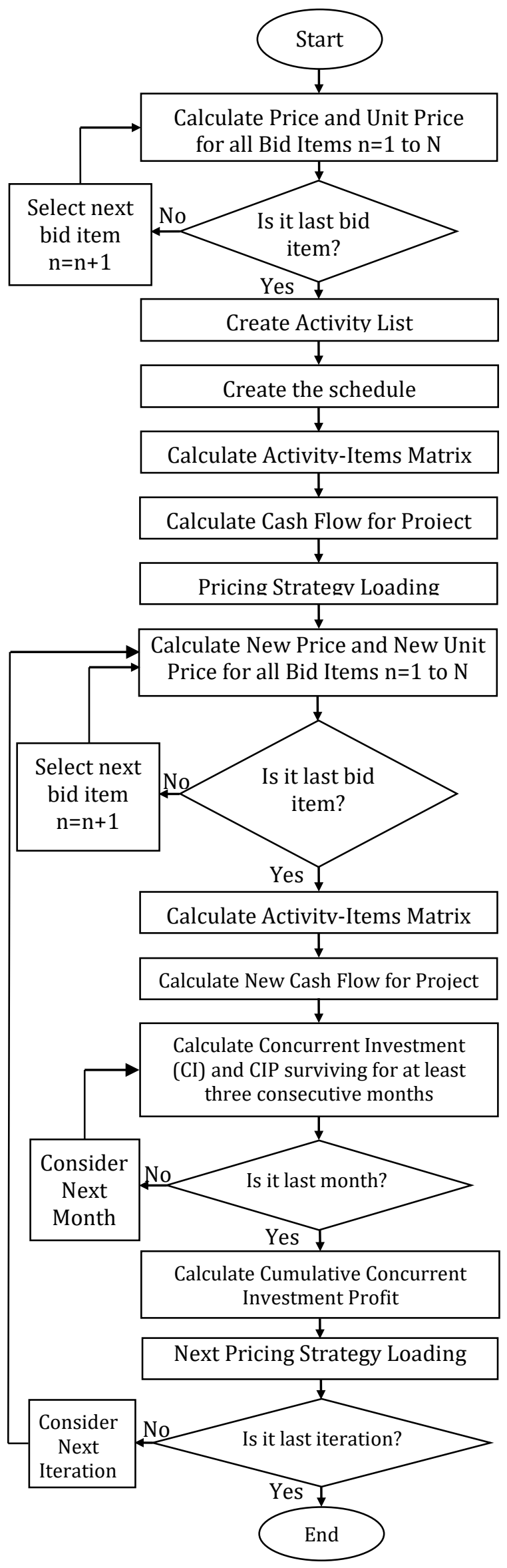

Figure 6. Flowchart of the proposed methodology

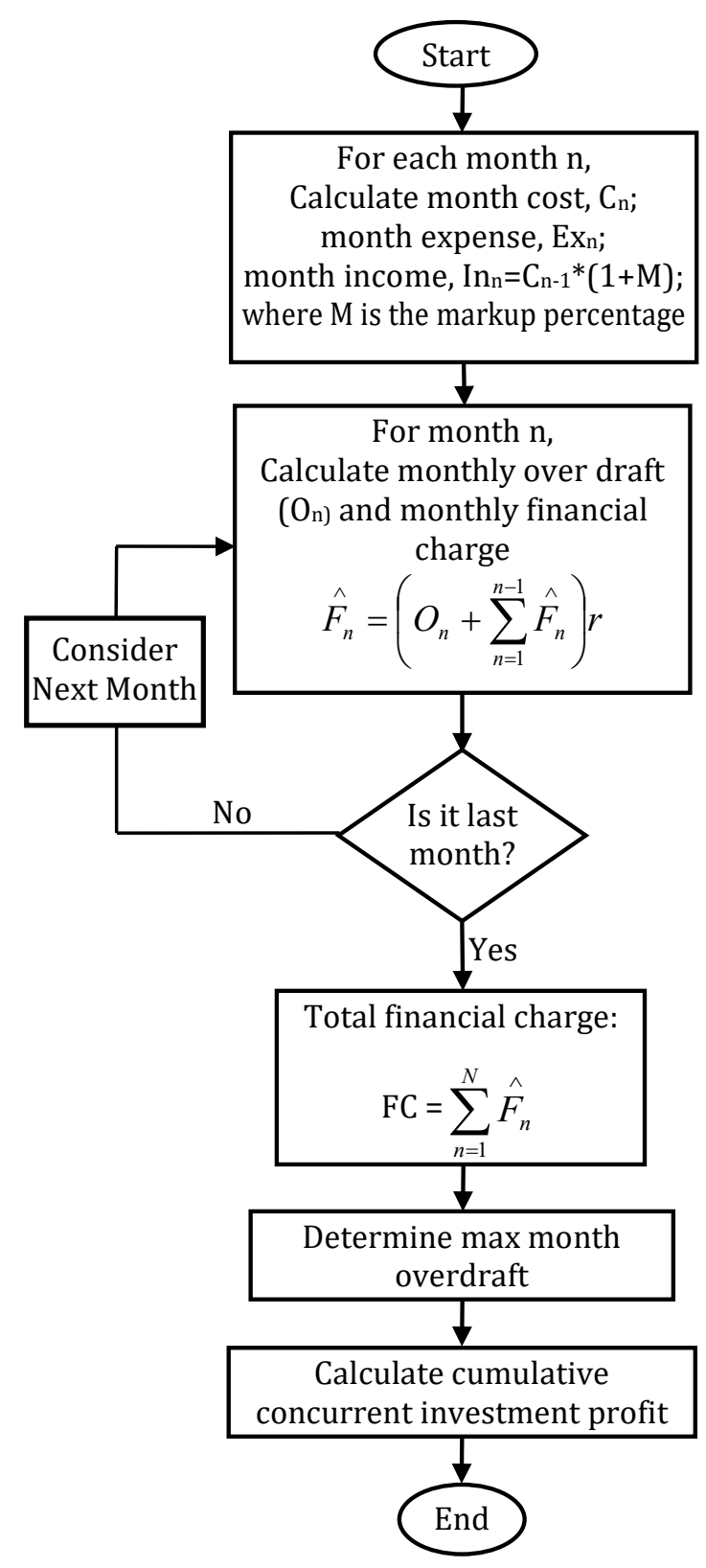

Figure 7. Flowchart of cash flow determination

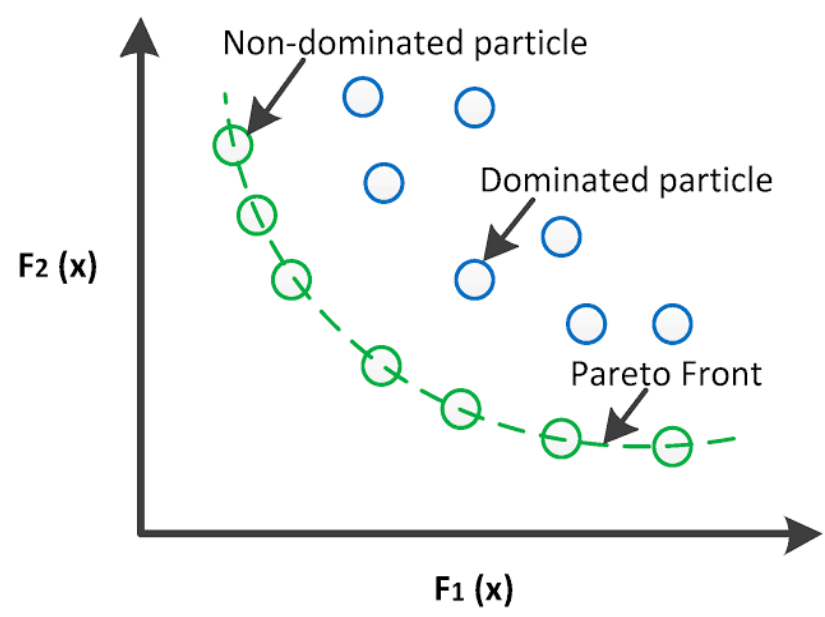

Figure 8. Concept of pareto-optimality (Mahesh et al. 2016) 
is evaluated against a predefined objective function in a search of the optimum BOQ items price according to this objective function. The methodology adopted in accomplishing this goal is to integrate various cash problem in one complete model.

2-Problem Constraints: In searching for solution to the cash flow problem, three constraint types are considered. Firstly, the resulting project duration $\mathrm{T}$ should not exceed the contract duration (project deadline date) $\mathrm{T}$ ' as given by Eq. (7). Secondly, each BOQ item price (Pi') can change within range $\pm 15 \%$ from its BOQ item price as given by Eq. (8). thirdly, the resulting tender price PT should equal the contract total bid price PT'.

$$
\begin{gathered}
\mathrm{T} \leq \mathrm{T}^{\prime} \\
\left(0.85 * \mathrm{P}_{\mathrm{i}}\right)<\mathrm{P}_{\mathrm{i}}{ }^{\prime}<\left(1.15^{*} \mathrm{P}_{\mathrm{i}}\right) \\
\mathrm{P}_{\mathrm{T}} \leq \mathrm{P}_{\mathrm{T}}{ }^{\prime}
\end{gathered}
$$

3-Model output data are optimized BOQ items price, optimized cash flow, and net cash flow diagram for the selected optimum scenario.

\section{Model Automation}

In order to facilitate the implementation of the developed model, this paper presents the development of a system to automate the proposed model. Details of the automated system used for optimizing the objectives of construction projects are provided. This section begins with describing the implementation media. Then, it describes an overview of the developed system structure. Next, it illustrates the ways of inputting data regarding schedule, cost, and cash flow analysis.

The implementation media of optimization model is a computerized system incorporating scheduling software and spreadsheet software. Commercial spreadsheets have many features including formatting, editing file management and database capabilities, a wide variety of special functions, statistical or optimization subroutines and the ability to represent data graphically (Gottfried and Burnett 1997; Quinn and Bederson 2014).

A scheduling tool is also needed to perform various scheduling calculations in a fast and professional way. Microsoft Project is a powerful scheduling tool that can be programmed in conjunction with Excel in an efficient way. An optimization tool is also needed to perform various optimization calculations in a fast and professional way. GaNetXL is an add-in program for Microsoft Excel that adds the possibility of using genetic algorithms to solve various optimization tasks. The main tab, as shown in Fig. 9, enables users to input the data and to optimize a project BOQ with different options.

The steps to use the computerized model are summarized as follows:

Steps 1 and 2 are Schedule Data and User input schedule data in MS-Project respectively.

Steps 3 and 4 are BOQ Pricing Data and User input BOQ data regarding construction methods in the excel sheet named "PROBLEM" respectively.

Steps 5 and 6 are Activity-Item Matrix Data (AI matrix) and User input price distribution of BOQ items on activities in order to connect among them in matrix consists of activities (rows) and BOQ items (columns) respectively.

Steps 7 and 8 are Cash Flow Data and User input data regarding cash flow respectively.

Step 9 is user is asked to specify optimization type, population size, number of generations and crossover type.

Then, in the Step 10 the automated system starts to generate random solutions in first iteration and calculates objective function(s),

Step 11 the solutions are updated. This process continues until convergence condition

\section{CASE STUdY}

The case study is "Beni Suef Power Station Project". The project is located in Beni Suef, Egypt. The owner of the project is the Ministry of Electricity and Renewable Energy, Egypt. The contractor is the EL-SEWEDY-PSP Company, Egypt. The project comprises the following main items:

1-Four model units $(4 \mathrm{xSCC}-8000 \mathrm{H} 2+1)$ with a nominal capacity of $1200 \mathrm{MW}$ each, with a total capacity of 4800 MW.

2-Each unit consists of two gas turbines with a nominal capacity of 400 megawatts each, two kettle to restore energy, one steam turbines with a nominal capacity of 400 MW.

3-Electro-mechanical works, and General and road works.

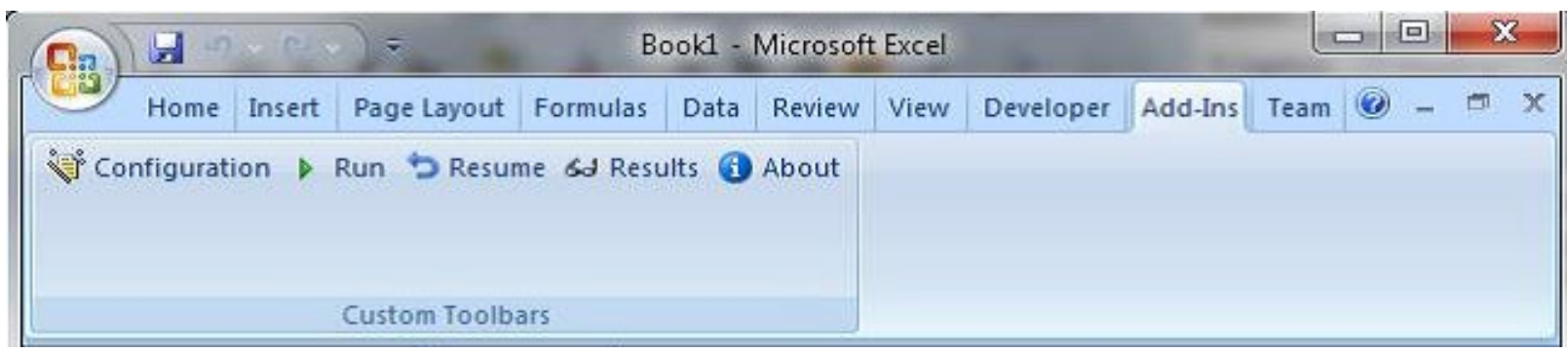

Figure 9. Main menu of the prototype system 


\section{A. Project Data}

The project has been divided into 299 activities. Descriptions, durations and direct costs of activities and logical dependencies between activities are given by Magdy (2019).. The project start date is set to $1 / 6 / 2016$. The initial schedule is generated using MS projects as shown in Fig. 10.

The project is planned to finish on $12 / 7 / 2018$, while the contract duration was set to be 26 months. The markup is assumed as $23.5 \%$. According to the contract conditions, the retention is $5 \%$, no advanced payment, and no incentive in case of early completion. It is assumed that the contractor pays $30 \%$ of the incurred cost immediately and $70 \%$ will be paid by the following month for the suppliers.

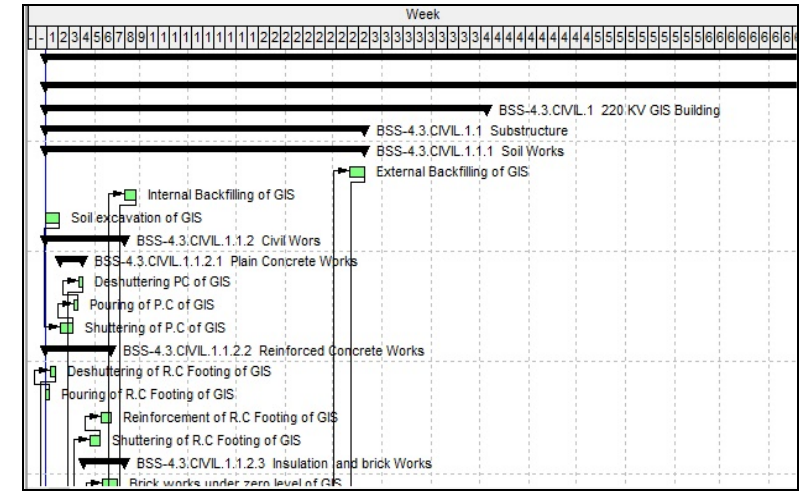

Figure 10. Part of original bar chart

\section{B. Cash Flow Optimization}

The original schedule with the direct cost listed by Magdy (2019) has a total price of 51,901,510 LE. Also, it has a maximum monthly overdraft of 5,227,581 LE and Cumulative Concurrent Investment Profit (CCIP) of 2,966,477 LE as shown in Fig. 11 to Fig. 13.

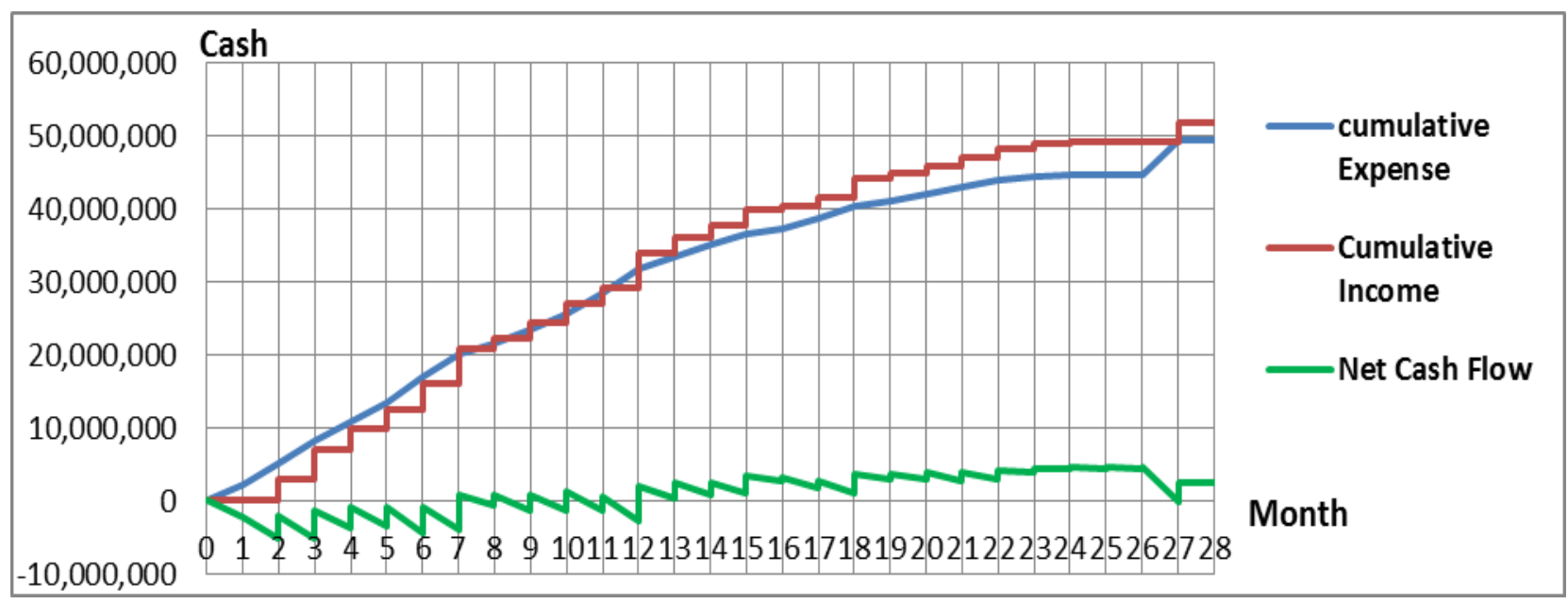

Figure 11. Original cash flow profiles

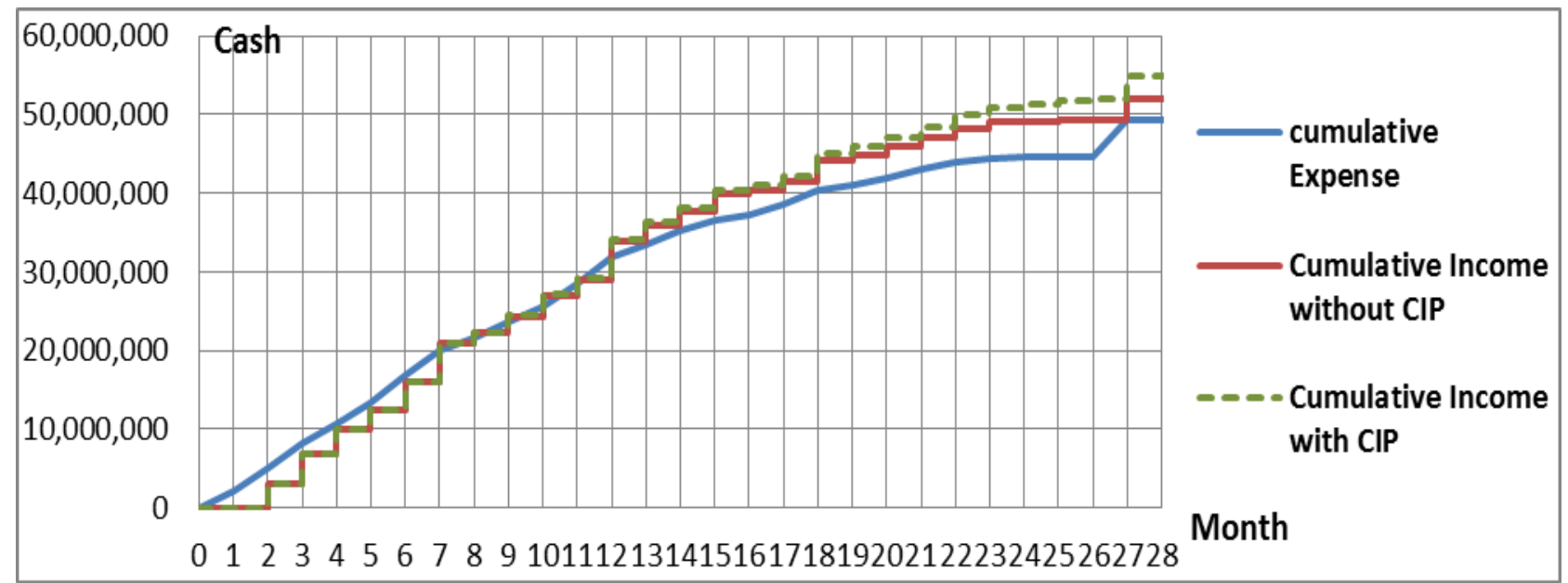

Figure 12. Original cash flow vs. Invested cash flow 
The optimization process started with the original schedule considering the linear cost distributions using two cases. First, using population size of 600 and number of generation (iterations) of 1000, the maximum monthly overdraft is minimized to be 5,144,223 LE with CCIP of 5,040,194 LE as shown in Table 1. Second, using population size of 1000 and number of generation (iterations) of 600 , the maximum monthly overdraft is minimized to be 5,144,223LE with CCIP of 5,021,598 LE as shown in Table 1 . Crossover type in both cases is Simple Multi point type. From optimization process that applied on two the previous cases as shown in Table 1, it is clear that both cases are very close in results.

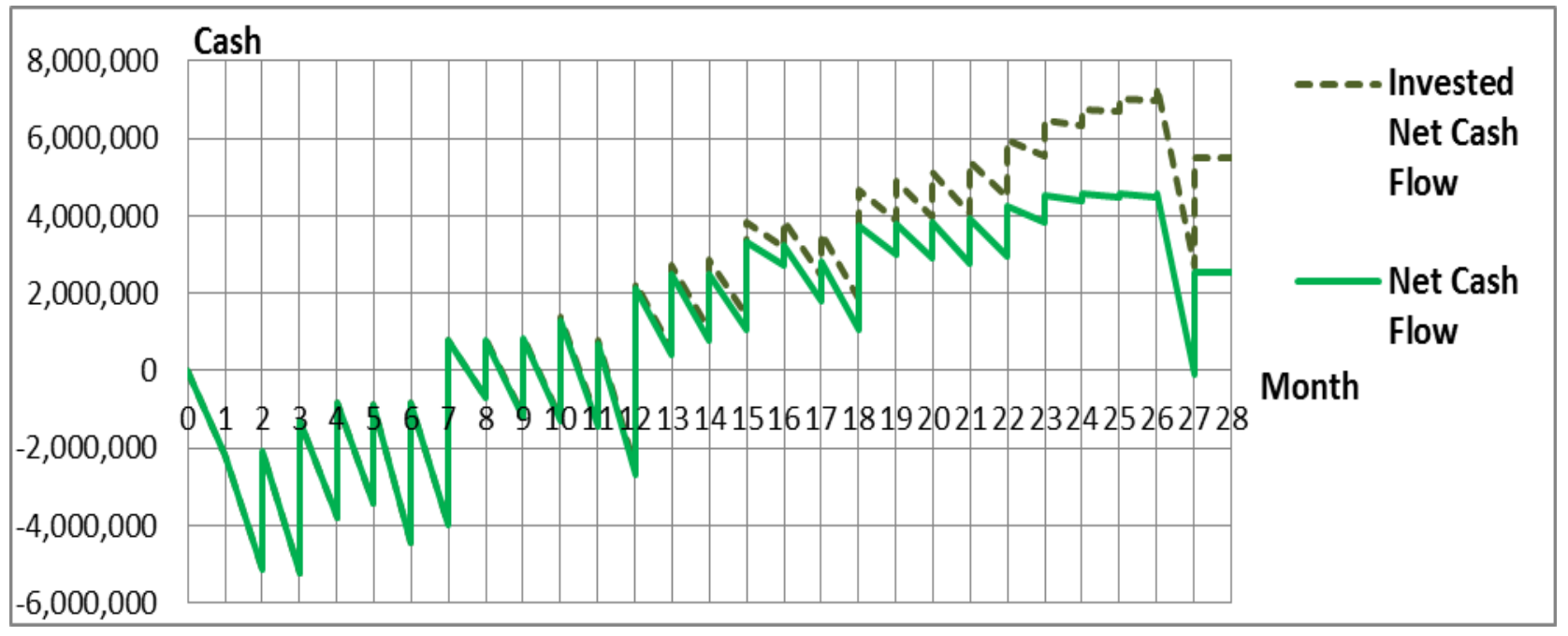

Figure 13. Original net cash flow vs. Invested net cash flow

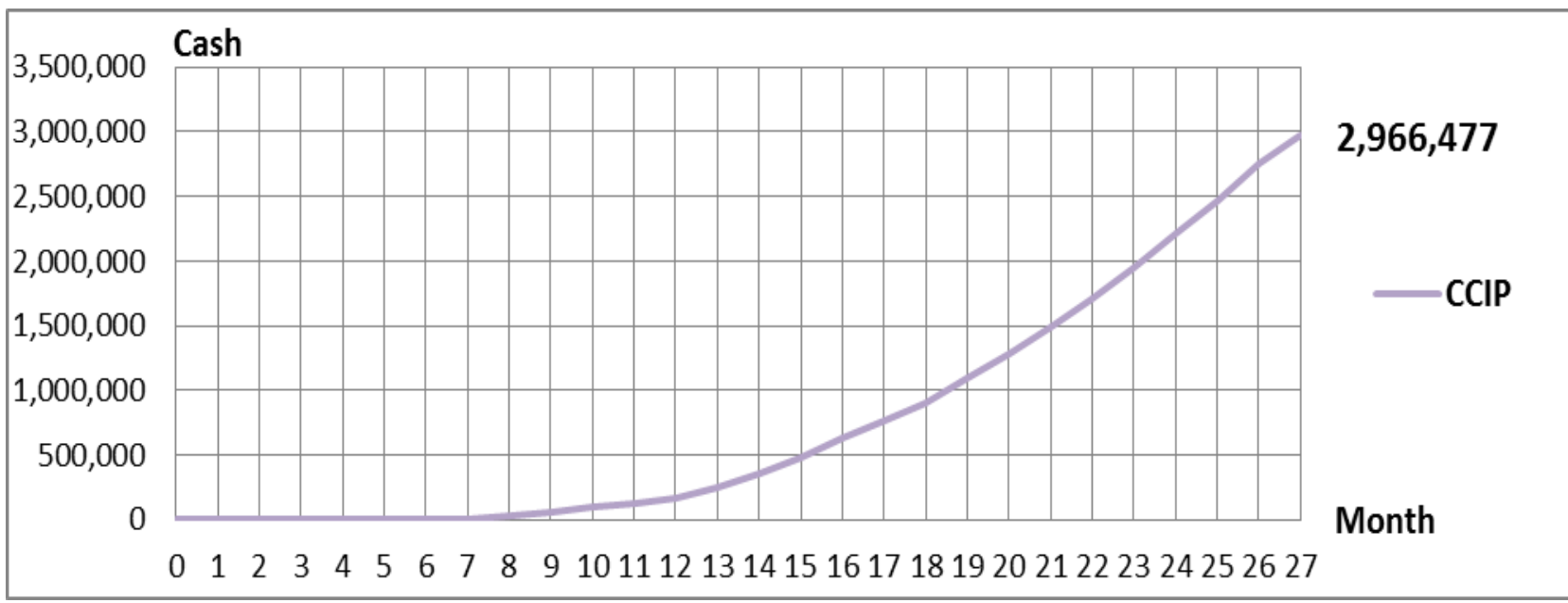

Figure 14. Original cumulative concurrent investment profit

TABLE I

OPTIMIZED Two CASES RESULTS

\begin{tabular}{|c|c|c|c|c|}
\hline Cases & $\begin{array}{c}\text { Population } \\
\text { Size }\end{array}$ & $\begin{array}{c}\text { Generation } \\
\text { Size }\end{array}$ & $\begin{array}{c}\text { Max } \\
\text { Overdraft } \\
\text { (LE) }\end{array}$ & CCIP (LE) \\
\hline Original & -1000 & $5,144,223$ & $5,040,194$ \\
\hline $\begin{array}{c}\text { Pop600- } \\
\text { Gen1000 }\end{array}$ & 600 & 500 & $5,144,223$ & $5,021,598$ \\
\hline $\begin{array}{c}\text { Pop1000- } \\
\text { Gen600 }\end{array}$ & 1000 & $600,966,477$ \\
\hline
\end{tabular}

Thus, it can be concluded that maximum overdraft does not affected with different population size and number of iterations whereas, a little difference in CCIP was obtained.

\section{Effect of Changing Percentage of Profit}

Changing percentage of profit affects the tender price and probability of winning the tender because the less percentage of profit the less tender price and therefore increased probability of winning. The process is taken into consider range of profit from $2 \%$ to $8 \%$ as shown in Fig. 15 and Fig. 16. 

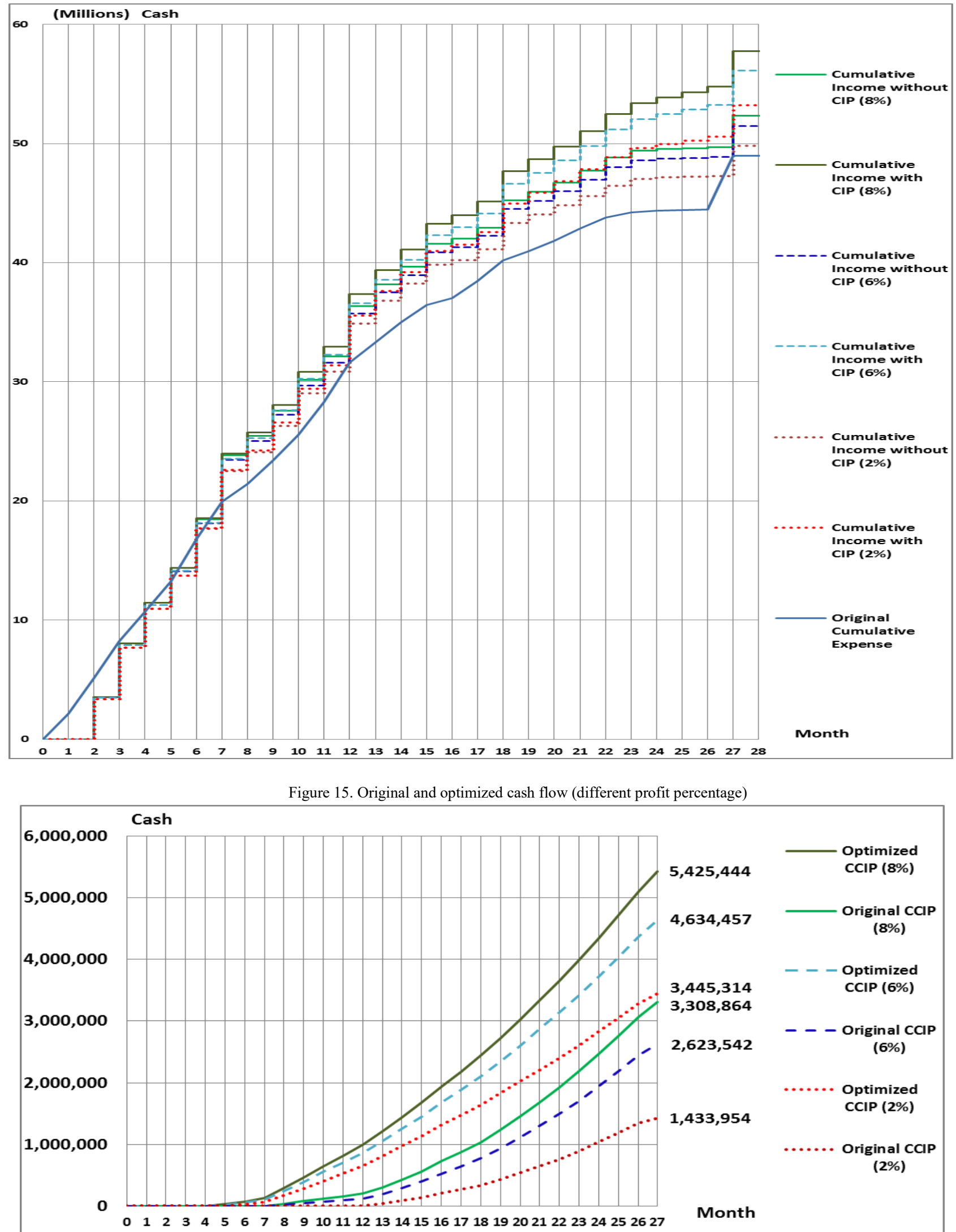

Figure 16. Original and optimized CCIP (different profit percentage) 
TABLE II

DIFFERENT PROFIT COMPARISON RESULTS

\begin{tabular}{|c|c|c|c|c|c|c|c|c|}
\hline profit & Case & $\begin{array}{c}\text { Tender } \\
\text { price (LE) }\end{array}$ & $\begin{array}{l}\text { NPV } \\
\text { (LE) }\end{array}$ & $\begin{array}{c}\text { Max } \\
\text { Overdraft } \\
\text { (LE) }\end{array}$ & $\begin{array}{l}\text { CCIP } \\
(\mathrm{LE})\end{array}$ & $\begin{array}{l}\text { Theoretical } \\
\text { profit (LE) }\end{array}$ & $\begin{array}{c}\text { Effective } \\
\text { profit } \\
\text { (LE) }\end{array}$ & $\begin{array}{c}\text { Effective } \\
\text { Profit } \\
\text { percentage }\end{array}$ \\
\hline \multirow{2}{*}{$2 \%$} & original & \multirow{2}{*}{$49,800,234$} & $44,718,178$ & $5,310,342$ & $1,433,954$ & 827,068 & $2,261,022$ & $4.5 \%$ \\
\hline & optimized & & $45,034,833$ & $5,117,421$ & $3,445,314$ & 827,068 & $4,272,382$ & $8.6 \%$ \\
\hline \multirow{2}{*}{$4 \%$} & original & \multirow{2}{*}{$50,640,745$} & $45,472,915$ & $5,291,927$ & $1,936,439$ & $1,427,052$ & $3,363,491$ & $6.6 \%$ \\
\hline & optimized & & $45,759,913$ & $5,137,196$ & $3,841,258$ & $1,427,052$ & $5,268,310$ & $10.4 \%$ \\
\hline \multirow{2}{*}{$6 \%$} & original & \multirow{2}{*}{$51,481,255$} & $46,227,652$ & $5,249,021$ & $2,623,542$ & $2,159,882$ & $4,783,424$ & $9.3 \%$ \\
\hline & optimized & & $46,521,443$ & $5,141,875$ & $4,634,457$ & $2,159,882$ & $6,794,339$ & $13.2 \%$ \\
\hline \multirow{2}{*}{$8 \%$} & original & \multirow{2}{*}{$52,321,765$} & $46,982,389$ & $5,206,149$ & $3,308,864$ & $2,892,525$ & $6,201,389$ & $11.8 \%$ \\
\hline & optimized & & $47,282,890$ & $5,146,576$ & $5,425,444$ & $2,892,525$ & $8,317,969$ & $15.6 \%$ \\
\hline
\end{tabular}

The majority of contractors depend on original (classical) profit only to achieve their cash objectives and neglect the power of compound investment that exists in CCIP. The results shown in Table 2 prove the importance of the CCIP which allows the contractor to choose less profit to increase the probability of tender winning and compensate the contractor with hidden CCIP.

\section{CONCLUSIONS}

In this paper, an optimization model for cash flow of construction project was developed. The developed model can be used to optimize construction BOQ item price based on multiple objectives. Some remarks were concluded and listed below:

1-The results of the cash flow model can be used to make crucial decisions, such as: 1) bid-no bid decision and 2) subcontract no subcontract decision. In the first decision, the contractor may refuse competing for a project when the monthly overdrafts are of high values even after enhancing. In the second decision, using subcontractor(s) for some activities may relief financial commitment for the main contractor;

2-The contractor can reduce the price of the tender and thus enhance the chance of winning the tender against other contractors by maximizing level of CCIP which leads to an increase in the profit;

3-Considering time-value of money via assessment of net present value (NPV) by changing BOQ item price within range $\pm 15 \%$. Especially if the owner needs to apply NPV on contractors;

4- Adjusting monthly overdrafts to be within certain limit is useful for contractors not only to meet financial constraints, but also to allow the contractor to compete for another parallel bid utilizing the extra saved amount of cash instead of being exhausted in one project. Also, in the pre-bid stage, the minimized financial charge increases project profit or decrease the bid price which in turn increases the probability of winning the bid;

5-Minimized level of monthly overdrafts reduces financial aspects of the project. This argument is based on the fact that assures the owner may evade from baying the invoice to the contractor if the required cash amount is very high. Higher overdraft values increase the probability of meeting problems with owners, especially when the owner is an agency or entity known by its stiff financial policy and eluding with contractors and their banks;

6-A case study was presented to validate the proposed model and to illustrate its use. The model can be particularly advantageous when the project duration is long or the contract terms are unfavorable. It is worth noting that minimizing monthly overdrafts doesn't guarantee maximization of cumulative concurrent investment profit because there is no specific relationship between objectives functions that subject to optimization.

\section{ACKNOWLEDGMENT}

Corresponding author wants to thank his supervisors for their valuable suggestions and help.

\section{REFERENCES}

[1] Afshar, A. and Amiri, H. (2010). "Risk-based approach to unbalanced bidding in construction projects." Engineering Optimization, 42(4), 369-85.

[2] Arafa, M. T. (1998). "Program for Cash Flow Optimization via Rescheduling of Engineering Projects." M.Sc. Thesis, Cairo University, Egypt.

[3] Awwad, R. and Ioannou, P. (2012). "A Risk-Sensitive Markup Decision Model, in. Hastak, M., Kandil, A.A' and Cai, H. (eds)" Proceedings of the 2012 Construction Research Congress, West 
Lafayette, IN, 21-23 May, American Society of Civil Engineers, Reston, VA, pp. 199-208.

[4] Baroum, S. M., and Patterson, J. H. (1996). "The Development of Cash Flow Weight Procedures for Maximizing the Net Present Value of a Project." Journal of Operations Management, Elsevier, Vol. 14, PP. 209-227.

[5] Cattell, D. W. (1987). "Item price loading." Proceeding, PACE'87 Progress in Architecture, Construction and Engineering, Vol. II, Johannesburg, South Africa, 1-20.

[6] Cattell, D. W., Bowen, P. A. and Kaka, A. P. (2008). "A Simplified Unbalanced Bidding Model." Journal of Construction Engineering and Management, 26:12, 1283-1290.

[7] Cattell, D.W., Bowen, P.A. and Kaka, A.P. (2011). "Proposed Framework for Applying Cumulative Prospect Theory to an Unbalanced Bidding Model." Journal of Construction Engineering and Management, 137(12), 1052-9.

[8] Christodoulou, S. E. (2008). "A Bid-unbalancing Method for Lowering a Contractor's Financial Risk." Construction Management and Economics, 26(12), 1291-302.

[9] Elazouni, A. M. and Gab-Allah, A. A. (2004). "Finance-Based Scheduling of Construction Project Using Integer Programming." Journal of Construction Engineering and Management, 130(1), 15-24.

[10]Elazouni, A. M. and Metwally, F. G. (2005). "Finance-Based Scheduling: Tool To Maximize Project Profit Using Improved Genetic Algorithms." Journal of Construction Engineering and Management, 131(4), 400-412.

[11]Gottfried, H. J. and Burnett, M. M. (1997). "Graphical definitions: making spreadsheets visual through direct manipulation and gestures." Proceedings of the IEEE Symposium on Visual Languages, p.246.

[12]Hegazy, T. (2001). "Computer-Based Construction Project Management." Prentice Hall Inc., New Jersey, USA.

[13]Hussein, I. (2009). "Pricing Tenders of construction." Journal of cost engineering, 51(1), 7-14.

[14]Lawrence, J. A. and Pasternack, B. A. (2002). "Applied Management Science: Modeling, Spreadsheet Analysis, and Communication for Decision Making." Copyright $\mathbb{C}$ by John Wiley and Sons Inc., New Jersey, USA.

[15]Lucko, G. and Su, Y. (2015). "Synthetic Cash Flow Model with Singularity Functions for Unbalanced Bidding Scenarios." Construction Management and Economics, 33:1, 35-54.

[16]Magdy, M. (2019). "Enhancing Cash Flow and Bidding Financial Statement through Optimization of Unbalanced Bid Supported with Concurrent Investment" Master of science Thesis, Tanta University, Tanta, Egypt.

[17]Mahesh, K., Nallagownden, P. and Elamvazuthi, I. (2016). "Advanced Pareto Front Non-Dominated Sorting MultiObjective Particle Swarm Optimization for Optimal Placement and Sizing of Distributed Generation." Journal of Energies, 9, 982.

[18]Miliken, J. (1996). "Bills of Quantities and the Tendering Process". Building Economist, 14-17.

[19]Mohagheghi, V., Mousavi, S. M., Vahdani, B. (2017). "Analyzing Project Cash Flow by a New Interval Type-2 Fuzzy Model with an Application to Construction Industry." Copyright (C) by Springer Science-i-Business Media, LLC.

[20]Mojahed, Sh. (2005). "A Project Improvement System for Effective Management of Construction Projects.” Ph.D. Thesis, Louisiana State University, Louisiana, USA.

[21]Odeyinka, H.A., Kelly, S. and Perera, S. (2009). "An Evaluation of the Budgetary Reliability of Bills of Quantities in Building Procurement." The construction and building research conference of the Royal Institution of Chartered Surveyors, University of Cape Town, 435-446.

[22]Onomehebhor, I. P. (2006). "Improvement of Construction Project Management Practice-Determinants and Effects of Stakeholders Satisfaction." Ph.D. Thesis, ESC-Lille Graduate School of Management, Lille, France.

[23]Quinn, A. J. and Bederson, B. B. (2014). "Efficient Human Computation for Decision Making With Spreadsheets." Proceedings of the 17th ACM Conference on Computer Supported Cooperative Work \& Social Computing (CSCW 2014), 1456-1466.

[24]Sanad, H. M. (2011). "Optimum Analysis of Construction Projects with Nonlinear Cash Flow." PhD Thesis, Tanta University, Tanta, Egypt.
[25] Statistic Brain. (2014). "Startup Business Failure Rate by Industry."(http://www.statisticbrain .com /startup-failure-byindustry/).

[26]Surety Information Office. (2012). "Why Do Contractors Fails?" (http://c.ymcdn.com/sites /www.surety.org/resource/resmgr/LearnAboutSurety/Why Do Contractors Fail.pdf).

[27]Tong, Y. and Lu, Y. (1992). "Unbalanced bidding on contracts with variation trends in client-provided quantities." Construction Management and Economics, 10, 69-80.

[28]Warszawski, A., and Sacks, R. (2004). "Practical Multifactor Approach to Evaluating Risk of Investment in Engineering Projects." Journal of Construction Engineering and Management, Vol. 130, No. 3, PP. 357-367.

[29]Yuan, X. X. (2011). "A correlated bidding model for markup size decisions." Journal of Construction Management and Economics, 29(11), 1101-19. 